\title{
Lethal hemolytic anemia-genital anomalies syndrome
}

INSERM

\section{Source}

INSERM. (1999). Orphanet: an online rare disease and orphan drug data base. Lethal hemolytic anemia-genital anomalies syndrome. ORPHA:1046

Waters-West syndrome is characterized by the association of lethal non-spherocytic, non-immune hemolytic anemia with abnormalities of the external genitalia (micropenis and hypospadias), flat occiput, dimpled earlobes, deep plantar creases, and increased space between the first and second toes. It has been described only once in two brothers who died a few hours after birth. The second-born infant had massive ascites and hepatosplenomegaly. The mother had two spontaneous abortions (at 6 and 12 weeks gestation) but gave birth to a normal girl, suggesting an autosomal or X-linked recessive mode of inheritance. Although the parents were not known to be consanguineous, they shared a French-Canadian and American Indian ethnic origin. 